\title{
Mechanical Characterization of DCPD and ENB Healing Systems in Glass Fibre Composites
}

\author{
IONUT SEBASTIAN VINTILA ${ }^{1}$, TEODOR BADEA ${ }^{1}$, SORIN DRAGHICI $^{2 *}$, \\ HORIA ALEXANDRU PETRESCU ${ }^{2}$, ANDREIA CUCURUZ ${ }^{3}$, HORIA IOVU ${ }^{4}$, \\ ANTON HADAR ${ }^{2,5,6}$ \\ ${ }^{1}$ National Research and Development Institute for Gas Turbines COMOTI, 220 D Iuliu Maniu Blvd, Bucharest Romania \\ ${ }^{2}$ University Politehnica of Bucharest, Department of Strength of Materials, 313 Splaiul Independenţei, 060032, Bucharest, \\ Romania \\ ${ }^{3}$ University Politehnica of Bucharest, Department of Medical Engineering, 1-7 Gheorghe Polizu Str., Bucharest, Romania \\ ${ }^{4}$ University Politehnica of Bucharest, Department of Bioresources and Polymer Science, 1-7 Gheorghe Polizu Str., \\ Bucharest, Romania \\ ${ }^{5}$ Academy of Romanian Scientists, 125 Calea Victoriei, 010071, Bucharest, Romania \\ ${ }^{6}$ Technical Sciences Academy of Romania, 26 Dacia Blvd, Bucharest, 010413, Romania
}

Abstract. The present paper is focused on evaluating the mechanical characterization of dicyclopentadiene (DCPD) and 5-ethylidene-2-norbornene (ENB) healing systems synthetized by insitu polymerisation. Both healing systems were embedded in glass fibre reinforced polymer (GFRP) composite and subjected to three-point bending test regime. Microstructural and FT-IR analysis showed the formation of microcapsules and a successful integration in the composite material. To observe the influence of temperature variation, some specimens were exposed to thermal cycling ($20^{\circ} \mathrm{C}$ to $\left.+100^{\circ} \mathrm{C}\right)$ for 12 hours and tested in the same conditions. It was observed that the addition of microcapsules in the composite material decreased its mechanical properties by $8 \%$ and $10 \%$ for DCPD system and ENB system respectively. Thermal cycling suggested a drop of $24 \%$ on bending strength for DCPD system and 17\% for ENB. Resting after 24 hours showed a healing recovery of $74 \%$ for DCPD healing system and of $97 \%$ for ENB system.

Keywords: Self-healing, GFRP composite, Mechanical test, Dicyclopentadiene, 5-ethylidene-2norbornene

\section{Introduction}

Since their first use in 1970 [1,2] the application of fibre reinforced composites (FRC) materials has developed rapidly. Nowadays, up to 20 million tons of composite materials are manufactured annually, for major industries like aeronautic, space, military, energy and construction. As these materials are consistently exposed to mechanical loads during their lifetime service, they are predisposed to delamination, split, fibre debonding etc., raising concerns about their structural integrity. These mechanical failures can be encountered either on the surface of the structure or interlaminar, being very difficult up to impossible to detect without non-destructive evaluation (NDE) methods. Moreover, if the material is exposed to harsh environment, the polymer composite can suffer degradation, therefore inducing small size defects known as microcracks. These microcracks can be formed either during the fabrication process or during the service of the composite structure, which can cause material failure, thus considerably reducing the lifespan of the whole structure [3-5]. Most common NDE methods to detect local damage and identify emerging failures in critical composite structures [6] are infrared thermography, electromagnetic testing, X-ray tomography and vibrothermography [7].

One of the solutions to locally repair the composite material without replacing the entire structure is to inject a chemically compatible resin and having good mechanical properties directly at the damaged area. Another method implies the removal of the damaged area and applying a patch from the same composite material. These solutions require manual intervention to the site and observation of

\footnotetext{
*email: sorin.draghici@upb.ro
} 
the damaged part that can be time-consuming, costly and ineffective if the damage is localized inside the material. To eliminate these efforts, a new method of repair has been introduced to the polymer composite materials, more precisely the natural mechanism of self-healing. The interest for this new method grew tremendously in the last decade and became an important field of study in the engineering applications of polymeric materials. Few years after the introduction of composite materials to the industry, Jud et al. [8] proposed the self-healing of polymeric materials in 1980 as a mean of healing invisible microcracks to increase the lifetime and safety of composite materials. As technology and material development matured, more approaches on the self-healing mechanism have been investigated firstly by Dry [9] who studied the feasibility of using passive materials as hollow fibers embedded into the matrix to deliver the healing agent. Her studies are considered a starting point for this healing mechanisms and was followed by others [10-17].

Nevertheless, with the existing intensive research on healing systems, the main problem remains the integration of such systems within the composite material, as it is rather difficult considering the geometry and scale of each structure and the prediction of defect presence. In addition, the prediction of the specific crack location appearance, nonetheless its propagation is difficult to predict in order to integrate the healing system in a certain region.

An assumption can be made where the structure is going to fail, by means of numerical simulations, but this implies that all the mechanical loads are very well defined, and even so, this is not perfectly accurate due to two main reasons. Firstly, the healing agents are formed from different materials and therefore possess different mechanical loads and being rather difficult to provide necessary input data for analysis. To date, there is no proper way to precisely indicate the behaviour of self-healing systems by means of strength analysis, as for other materials. Secondly, the behaviour of stratified materials during mechanical loads. Fibre reinforced polymers (FRP) materials rise the assumption on which layer the crack appears in order to know where to apply the healing system. The latter is more easily identifiable through numerical simulation, but a rigorous algorithm must be foreseen [18-20].

Another option could be the fabrication and integration of a thin film (acting as a coating) or a microvascular network between the FRP layers, as indicated by the strength analysis. However, as this film of network does not have a specific mechanical strength, it is considered a defect in the composite structure. This could be the reason why most research in this area is concentrated in evaluating and validating several self-healing mechanisms and concepts [3,21,22] only at sample level. The industrialization of the self-healing system is still far from being realized.

For this study, dicyclopentadiene (DCPD) and 5-ethylene-2-norbornene (ENB) filled microcapsules are used as healing systems embedded in the glass fibre polymer composite specimens. Microcapsules containing these healing agent have properties such as acceptable strength, durability, and tremendous bonding to the base material [13]. Both urea-formaldehyde (UF) capsules containing DCPD and ENB agents are created by in-situ polymerization in the presence of an oil-in-water emulsion in order to meet the basic requirements for a self-healing process. The addition of capsules into the resin leads to a considerable effect on the mechanical properties of the material.

\section{Materials and methods}

\subsection{Manufacturing of healing systems}

Materials used for the synthesis of both UF-DCPD and MUF-ENB microcapsules are presented in Table 1. All materials were procured from Sigma-Aldrich.

Table 1. Chemical substances used in in-situ fabrication of DCPD and ENB microcapsules

\begin{tabular}{|c|c|c|c|}
\hline Material & Molecular formula & Physical properties & Role \\
\hline Urea & $\mathrm{CH}_{4} \mathrm{~N}_{2} \mathrm{O}$ & $\begin{array}{c}\text { Crystalline, white powder. } \\
\text { Melting point 133-135 }{ }^{\circ} \mathrm{C}\end{array}$ & $\begin{array}{c}\text { Formation of the capsule } \\
\text { shell in the aqueous state }\end{array}$ \\
\hline Melamine & $\mathrm{C}_{3} \mathrm{H}_{6} \mathrm{~N}_{6}$ & $\begin{array}{c}\text { White powder. Melting point at } \\
345^{\circ} \mathrm{C}\end{array}$ & Formation of capsule shell \\
\hline
\end{tabular}




\begin{tabular}{|c|c|c|c|}
\hline $\begin{array}{l}\text { Resorcinol }(1,3- \\
\text { benzenediol) }\end{array}$ & $\mathrm{C}_{6} \mathrm{H}_{4}(\mathrm{OH})_{2}$ & $\begin{array}{l}\text { White crystals. Melting point } \\
\qquad 113^{\circ} \mathrm{C}\end{array}$ & $\begin{array}{l}\text { Blending resin with } \\
\text { formaldehyde }\end{array}$ \\
\hline Formaldehyde & $\mathrm{CH}_{2} \mathrm{O}$ & Colorless aqueous solution & Formation of capsule shell \\
\hline $\begin{array}{l}\text { Dicyclopentadiene } \\
\text { (DCPD) }\end{array}$ & $\mathrm{C}_{10} \mathrm{H}_{12}$ & $\begin{array}{c}\text { Solid state (gel-like state at } \\
\text { room temperature). Melting } \\
\text { point } 32,5^{\circ} \mathrm{C}\end{array}$ & Monomer-capsule core \\
\hline $\begin{array}{l}\text { 5-Ethylidene-2- } \\
\text { norbornene }\end{array}$ & $\mathrm{C}_{9} \mathrm{H}_{12}$ & $\begin{array}{c}\text { Colourless liquid with an odour } \\
\text { of turpentine. Melting point at - } \\
80^{\circ} \mathrm{C} \text { and Boiling point at } \\
146^{\circ} \mathrm{C} \text {. }\end{array}$ & Monomer-capsule core \\
\hline Maleic anhydride & $\mathrm{C}_{2} \mathrm{H}_{2}(\mathrm{CO})_{2} \mathrm{O}$ & Solid state. White powder & Emulsifier \\
\hline Ammonium chloride & $\mathrm{NH}_{4} \mathrm{Cl}$ & Solid state. White powder & Formaldehyde hardener \\
\hline Sodium hydroxide & $\mathrm{NaOH}$ & Solid state. White powder & Rising solution $\mathrm{pH}$ \\
\hline $\begin{array}{c}\text { Sodium lauryl sulfate } \\
\text { (SLS) }\end{array}$ & $\begin{array}{c}\mathrm{CH} 3(\mathrm{CH} 2) 10 \mathrm{CH} 2 \\
(\mathrm{OCH} 2 \mathrm{CH} 2) \mathrm{nOSO} 3 \mathrm{Na} \\
\end{array}$ & Powder soluble in water & Emulsifier - oil solidification \\
\hline Hydrochloric acid & $\mathrm{HCl}$ & $\begin{array}{c}\text { Aqueous solution with strong } \\
\text { odor }\end{array}$ & Lowering solution $\mathrm{pH}$ \\
\hline Polyvinyl alcohol (PVA) & $(\mathrm{C} 2 \mathrm{H} 4 \mathrm{O}) \mathrm{x}$ & Melting point at $200^{\circ} \mathrm{C}$ & Separation film \\
\hline
\end{tabular}

\subsection{Synthesis of UF-DCPD microcapsules}

In a $600 \mathrm{ml}$ beaker, two solutions were prepared separately, a solution containing $150 \mathrm{~mL}$ distilled water, $7 \mathrm{~g}$ urea, $0.5 \mathrm{~g}$ resorcinol and $0.5 \mathrm{~g} \mathrm{NH}_{4} \mathrm{Cl}$ and a solution containing $100 \mathrm{~mL}$ co-polymer $5 \mathrm{wt} \%$ maleic anhydride. Both solutions were mixed until homogenization using a hot plate with a magnetic stirrer (model C-MAG HS 10) at $500 \mathrm{rpm}$ for $10 \mathrm{~min}$. The solution $\mathrm{pH}$ was adjusted to 3.5 using 10 vol\% $\mathrm{NaOH}$ and $10 \mathrm{vol} \% \mathrm{HCl}$ and the temperature was increased to $35{ }^{\circ} \mathrm{C}$ to prevent the DCPD monomer to crystalize when added. Considering this, in a $200 \mathrm{~mL}$ glass beaker $60 \mathrm{~g}$ of DCPD was weighted (OHAUS PA224 analytical balance) and heated at $35^{\circ} \mathrm{C}$. After the DCPD monomer became liquefied it was poured over the previous mixture solution, under continuous stirring for approximately $5 \mathrm{~min}$ to form microspheres. A formaldehyde $37 \%$ solution $(0.23 \mathrm{~mL}, 18.91 \mathrm{~g})$ was made and introduced after microspheres began to form. The temperature was increased at $50{ }^{\circ} \mathrm{C}$ and the solution was left under continuous stirring at $500 \mathrm{rpm}$ for $2 \mathrm{~h}$. During this, the initially formed healing agent (DCPD) microspheres are wrapped in a polymeric urea-formaldehyde layer. After $20 \mathrm{~min}$, the whitening of the DCPD microspheres was observed, meaning that the process of coating them with urea-formaldehyde polymer is carried out under good conditions, as presented in Figure 1a. After two hours, the solution was left to cool at room temperature while the synthesized microcapsules precipitates on the bottom. The microcapsule suspension is again diluted with $200 \mathrm{~mL}$ of distilled water and filtered under vacuum, after which the microcapsules are washed 3 times with $500 \mathrm{~mL}$ distilled water to remove any traces of uncoated monomer that adheres to the surface of the microcapsules at the time of recrystallization. The suspension was then left to dry for $24 \mathrm{~h}$ in a desiccator at room temperature $\left(21 \pm 1{ }^{\circ} \mathrm{C}\right)$. Microstructural analysis of DCPD microcapsules are presented in Figure 1b and c, using Olympus optical microscope GX and high resolution scanning electron microscope FEI Inspect F50.
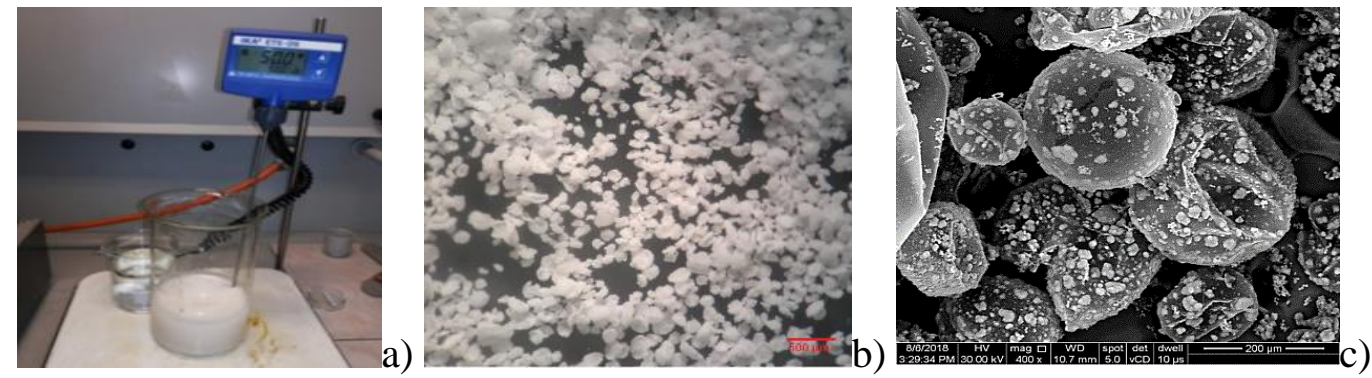

Figure 1. a) Emulsion of UF-DCPD microcapsules; b) stereomicroscope image and

c) SEM images of microcapsule agglomeration after $24 \mathrm{~h}$ drying at room temperature 


\subsection{Synthesis of MUF-ENB microcapsules}

Four separate solutions were required for the in-situ fabrication process of MUF-ENB microcapsules. For the first solution, in a $100 \mathrm{~mL}$ beaker, $0.61 \mathrm{~g}$ urea and $30 \mathrm{~mL}$ distilled water were mixed under continuous stirring until homogenization for about $10 \mathrm{~min}$. The second solution comprises the melamine-formaldehyde pre-polymer. In $70 \mathrm{~mL}$ of distilled water, $3.81 \mathrm{~g}$ of melamine and $6.89 \mathrm{~g}$ of formaldehyde (37\%) were introduced and left for $25 \mathrm{~min}$ at $70^{\circ} \mathrm{C}$ to react, subsequent being cooled down to room temperature. For the third solution, a $50 \mathrm{~mL}$ beaker was used to homogenize $30 \mathrm{~mL} 0.5 \mathrm{wt} \% \mathrm{SLS}$ at $70{ }^{\circ} \mathrm{C}$ for 20 minutes. The last solution was prepared from $30 \mathrm{ml}$ $6.3 \mathrm{wt} \%$ polyvinyl alcohol under continuous stirring for $2 \mathrm{~h}$ at room temperature. After the first solution was prepared, the stirring rate was increased to $300 \mathrm{rpm}$. SLS and PVA solutions were added to the admixture and the stirring rate was again increased to $500 \mathrm{rpm}$. After 10 to $15 \mathrm{~min}$, the solution was homogenized and $30 \mathrm{~mL}$ of ENB was slowly ported to the admixture. Because it is not miscible with water, under continuous stirring it forms spherulites. The stirring rate was kept at $500 \mathrm{rpm}$ for 10 minutes at ambient temperature afterwich the temperature was raised to $40^{\circ} \mathrm{C}$ for another $10 \mathrm{~min}$. To obtain the MUF-ENB microcapsules, the temperature was raised to $86^{\circ} \mathrm{C}$ and kept for $320 \mathrm{~min}$. After the reaction was completed, the hot plate was turned off and the solution left under continuous stirring until it reached room temperature. At ambient temperature, the stirring was turned off and the solution was left for 30 min until deposition of microcapsule, then vacuum filtered and rinsed three times with $300 \mathrm{~mL}$ of distilled water. Microcapsule suspension was left to dry in a desiccator at room temperature, $21 \pm 1^{\circ} \mathrm{C}$ for $24 \mathrm{~h}$. After drying, the microcapsule tends to agglomerate but with a mild stirring they were easily separated. The fact that the obtained microcapsules were separated easily shows that the respective batch has been successfully prepared. The blue colour of the microcapsules is due to the PVA solution. Figure 2 illustrates the MUF-ENB emulsion as well as microstructural analysis of the batch.
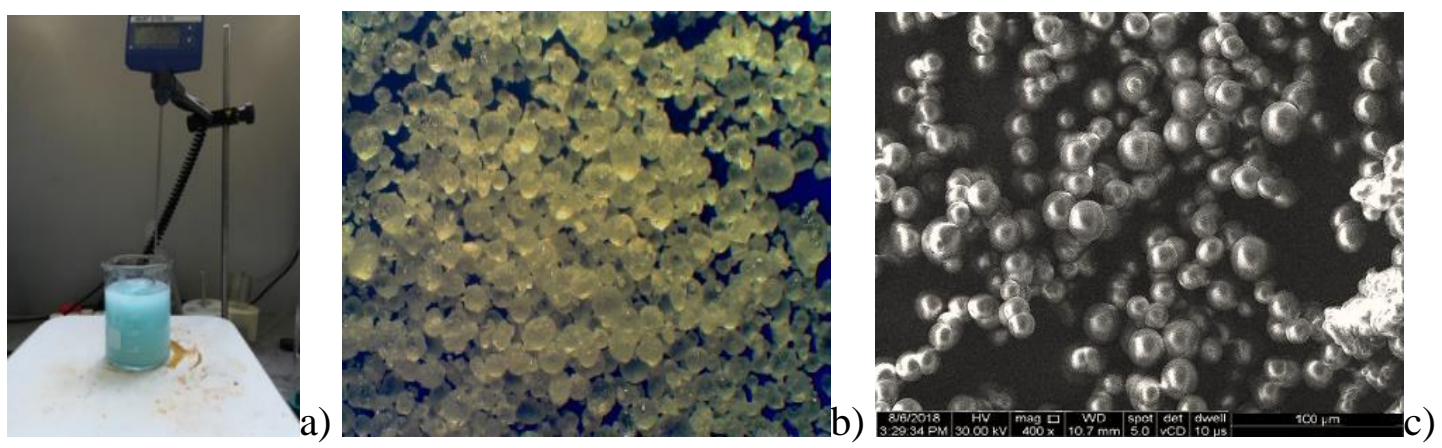

Figure 2. a) Emulsion of PUF-ENB microcapsules; b) stereomicroscope image and c) SEM images of microcapsule agglomeration after $24 \mathrm{~h}$ drying at room temperature

\subsection{Fourier-transform infrared spectroscopy (FT-IR) analysis}

In order to verify that the microcapsules were successfully synthesized, FT-IR analysis was carried out to UF-DCPD and PUF-ENB microcapsules The synthesized products were characterized by FTIR using a Nicolet iS50FT-IR (Nicolet, MA, USA) spectrometer equipped with a DTGS detector which provides information with a high sensitivity in the range of $4000 \mathrm{~cm}^{-1}$ and $400 \mathrm{~cm}^{-1}$ at a resolution of $4 \mathrm{~cm}^{-1}$. Each spectrum was obtained by co-adding 32 scans. The analysis is presented in figure 3, where constituents shell and core elements are observed after FT-IR analysis. These spectra confirm that the shell material of the capsules contains UF polymer. Furthermore, the capsules FTIR spectra contain entirely the core and shell peaks. Thus, the FT-IR results proved the successful encapsulation of DCPD and ENB monomers in the UF/MUF shell. 


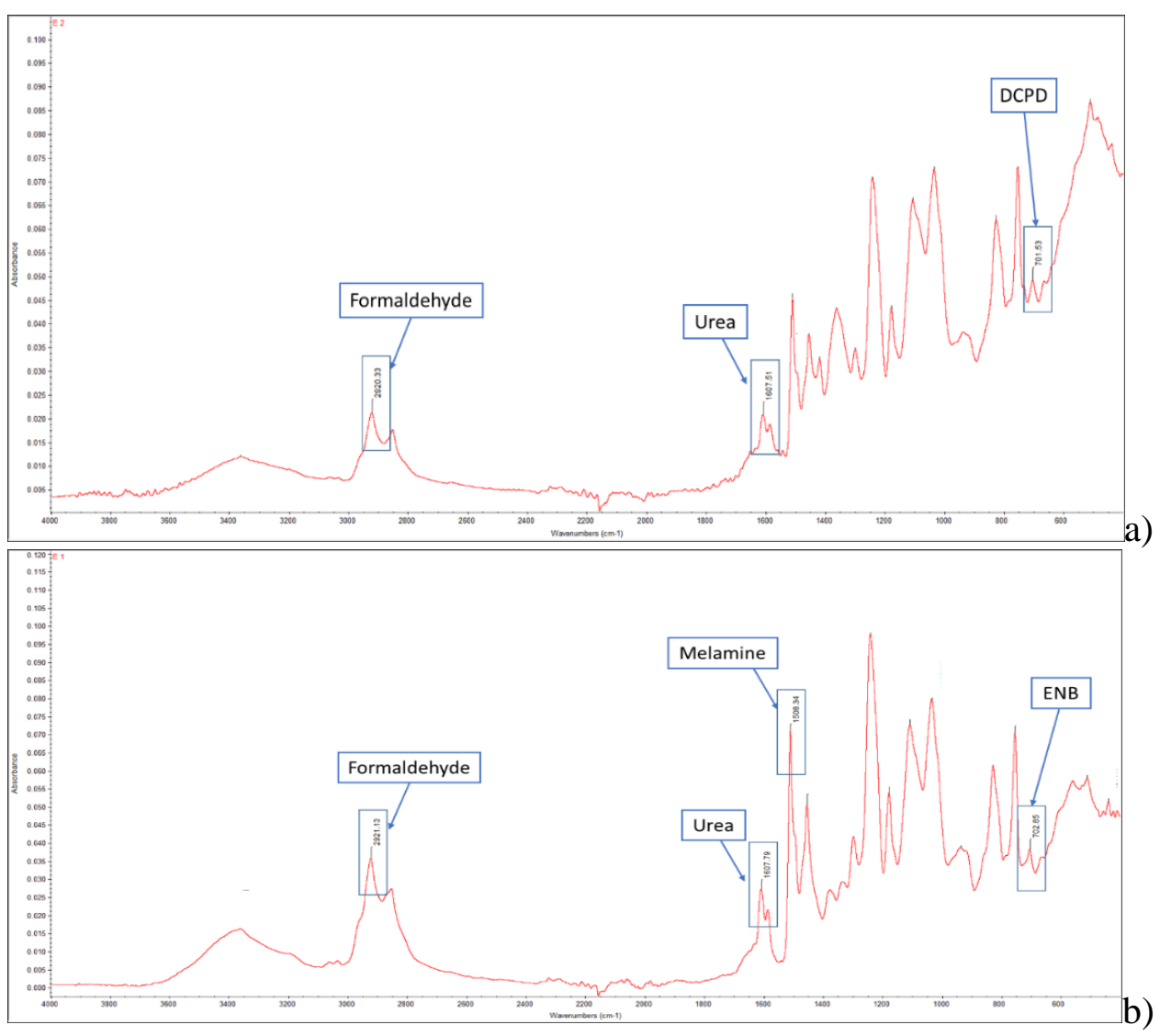

Figure 3. FT-IR spectra of main a) UF-DCPD and

b) MUF-ENB microcapsule constituents

\subsection{DSC analysis}

For the differential scanning calorimetry (DSC) analysis, Perkin Elmer 8000 was used to investigate the reactivity of the prepared capsules. Small amounts of samples (10-15 mg) were heated from 50 to $200^{\circ} \mathrm{C}$ at a rate of $20^{\circ} \mathrm{C} / \mathrm{min}$ in a $\mathrm{N}_{2}$ environment. According to the analysis presented in Figure 4, it was determined that the UF-DCPD glass transition temperature $(\mathrm{Tg})$ is $107.80 \mathrm{C}$ and $115^{\circ} \mathrm{C}$ for MUF-ENB respectively. The Tg difference between the two healing systems is due to their componence, ENB system having melamine in the core shell which has a very high melting point $\left(345^{\circ} \mathrm{C}\right)$.

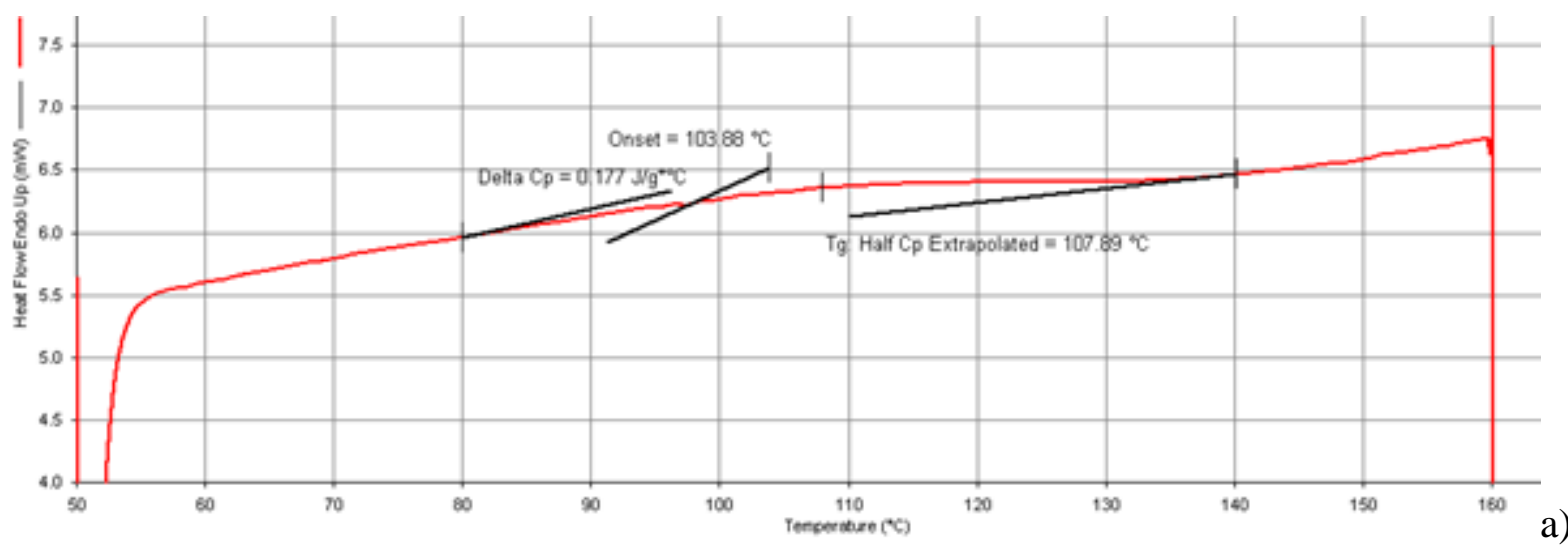




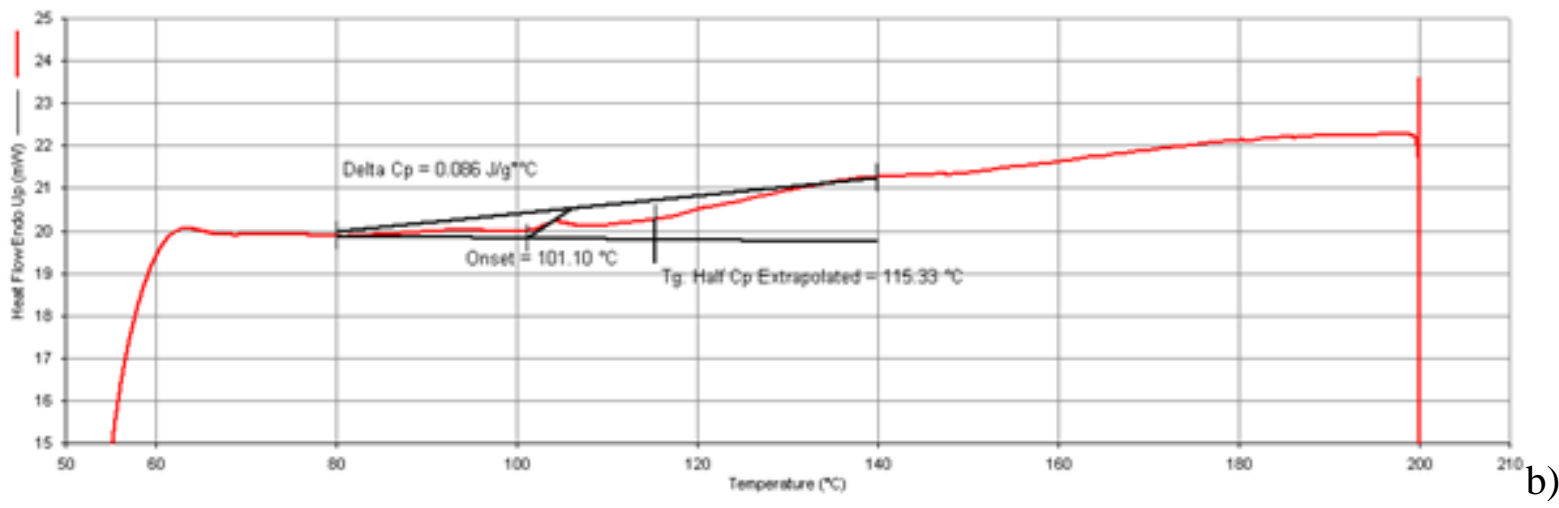

Figure 4. DSC analysis of the synthetized microcapsules a) UF-DCPD and b) MUF-ENB

To evaluate the healing efficiency of the proposed DCPD and ENB systems, three-point bending specimens were fabricated. The integration of healing systems and manufacturing process is presented hereafter.

\subsection{Three-point bending specimen fabrication}

Materials used in the specimen manufacturing process are M9.6GF/37\%/300H8/G prepreg (Hexcel), epoxy resin compatible with prepreg matrix (Resoltech 1050/1058), DCPD microcapsules, ENB microcapsules and Grubbs first generation catalyst.

For a single specimen having 100x15mm (SR EN ISO 178 Determination of bending properties), seven plies of M9.6GF were used, thus a total of 175 plies were cut at $\left[0^{\circ} / 90^{\circ}\right]$ to manufacture all 25 specimens, presented in table 2, required for this testing regime. The stacking sequence configuration was as follows: $\mathrm{Pp} / \mathrm{Pp} / \mathrm{SH} / \mathrm{Pp} / \mathrm{SH} / \mathrm{Pp} / \mathrm{SH} / \mathrm{Pp} / \mathrm{SH} / \mathrm{Pp} / \mathrm{Pp}$ where $\mathrm{Pp}$ represents one M9.6GF prepreg ply and $\mathrm{SH}$ represents the healing system. The healing system is composed of DCPD microcapsules with Grubbs catalyst and ENB microcapsules with Grubbs catalyst respectively.

To embed the healing system in the composite material according to the above stacking sequence, the microcapsules and the catalyst were firstly blended with Resoltech resin. By calculating the surface area of one specimen on which the healing system needs to be applied with respect to the stacking sequence, a total mass of $2 \mathrm{~g}$ of resin was found adequate for the admixture. Accordingly, the mass of microcapsules and catalyst was calculated corroborated with their respective percentage presented in Table 2. For each specimen, the amount of healing system was increased in order to evaluate the healing efficiency and the effect that the healing system has over the mechanical properties of the material.

Table 2. Specimen configurations for three-point bending testing

\begin{tabular}{|c|c|c|c|c|c|}
\hline \multirow{4}{*}{$\begin{array}{c}\text { Specimen } \\
\text { codification }\end{array}$} & Flex_Ref_1 & Flex_Ref_2 & Flex_Ref_3 & Flex_Ref_4 & Flex_Ref_5 \\
\cline { 2 - 6 } & Flex_DCPD_1 & Flex_DCPD_2 & Flex_DCPD_3 & Flex_DCPD_4 & Flex_DCPD_5 \\
\cline { 2 - 6 } & Flex_ENB_1 & Flex_ENB_2 & Flex_ENB_3 & Flex_ENB_4 & Flex_ENB_5 \\
\cline { 2 - 6 } & $\begin{array}{c}\text { Flex_TC_DCPD_ } \\
\text { Flex_TC_ENB_1 }\end{array}$ & $\begin{array}{c}\text { Flex_TC_DCPD_ } \\
2\end{array}$ & $\begin{array}{c}\text { Flex_TC_DCPD_TC } \\
\text { Flex_ENB_2 }\end{array}$ & $\begin{array}{c}\text { Flex_TC_DCPD_ } \\
4\end{array}$ & $\begin{array}{c}\text { Flex_TC_DCPD_ } \\
5\end{array}$ \\
\hline Resin qty (g) & 1,5 & 1,5 & 1,5 & 1,5 & 1,5 \\
\hline $\begin{array}{c}\text { Hardener qty } \\
\text { (g) }\end{array}$ & 0,5 & 0,5 & 0,5 & 0,5 & 0,5 \\
\hline $\begin{array}{c}\text { Microcapsule } \\
\text { s (g) }\end{array}$ & $5 \%(0,1)$ & $7 \%(0,14)$ & $10 \%(0,2)$ & $12 \%(0,24)$ & $15 \%(0,3)$ \\
\hline $\begin{array}{c}\text { Grubbs } \\
\text { Catalyst (g) }\end{array}$ & $2 \%(0,04)$ & $2,5 \%(0,05)$ & $4 \%(0,08)$ & $4,5 \%(0,09)$ & $6 \%(0,12)$ \\
\hline
\end{tabular}

Flex - Bending test; Ref - reference specimen; DCPD - microcapsules containing DCPD as healing agent;

ENB - microcapsules containing ENB as healing agent; TC - Thermal cycles 
A $50 \mathrm{~mL}$ beaker was used to mix the resin, microcapsules and catalyst. A $10 \%$ mas acetone was added to each mixture to decrease the resin viscosity for a better dispersion of microcapsules. The beaker was placed on a magnetic stirrer hot plate, set at $250 \mathrm{rpm}$ to prevent microcapsule rupture and $40^{\circ} \mathrm{C}$ in order to evaporate the added acetone. After the solution was homogenized, it was weighted and equally poured over each prepreg layer according to the stacking sequence, as seen in figure 5 . The same procedure was applied to each specimen. After all composite specimens were made, auxiliary materials like peel ply, release film, vacuum bag film and sealant tape was used to create the vacuum bag for the manufacturing stage. The curing cycle was set at $80^{\circ} \mathrm{C}$ for $510 \mathrm{~min}$ under constant vacuum. The pink colour is given by the addition of Grubbs catalyst in the mixture.

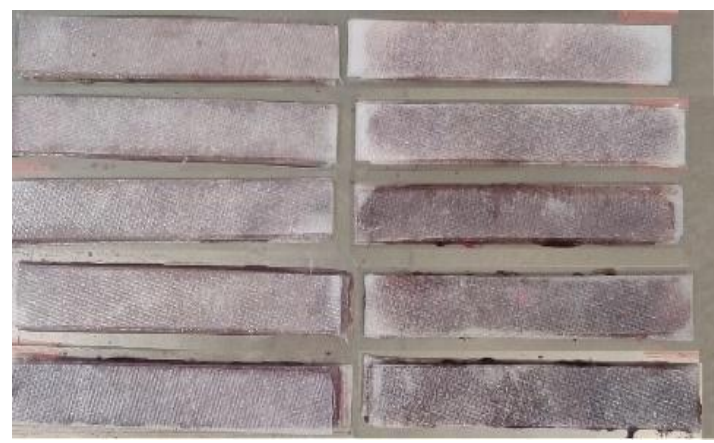

Figure 5. Bending specimens with embedded DCPD microcapsules (left) and ENB microcapsules (right) before curing cycle

\section{Results and discussions}

\subsection{Mass loss}

Mass of each specimen was measured before (BTC) and after thermal cycles (TC) and is presented in figure 6 , along with reference ones. It was observed that for the bending specimens, the average mass loss after TC was about 3\% which can be due to the degradation of healing agent components and due to some unreacted epoxy groups from the lay-up process of the healing system on the prepreg surface.

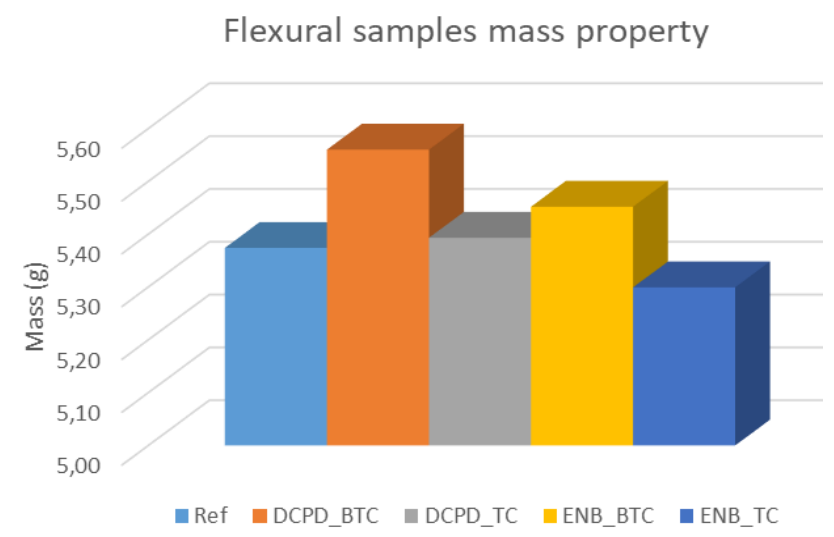

Figure 6. Mass loss average of bending specimens

\subsection{Microstructural analysis}

SEM analysis was performed to observe the correct integration of synthesized microcapsules within the composite material. As seen from below figures, the diameter for DCPD microcapsules ranges between 100 and $250 \mu \mathrm{m}$ while ENB microcapsules have a diameter varying between 30 and $100 \mu \mathrm{m}$. Also, residue was observed in the cavities during SEM analysis, which can be due to sample preparation. 


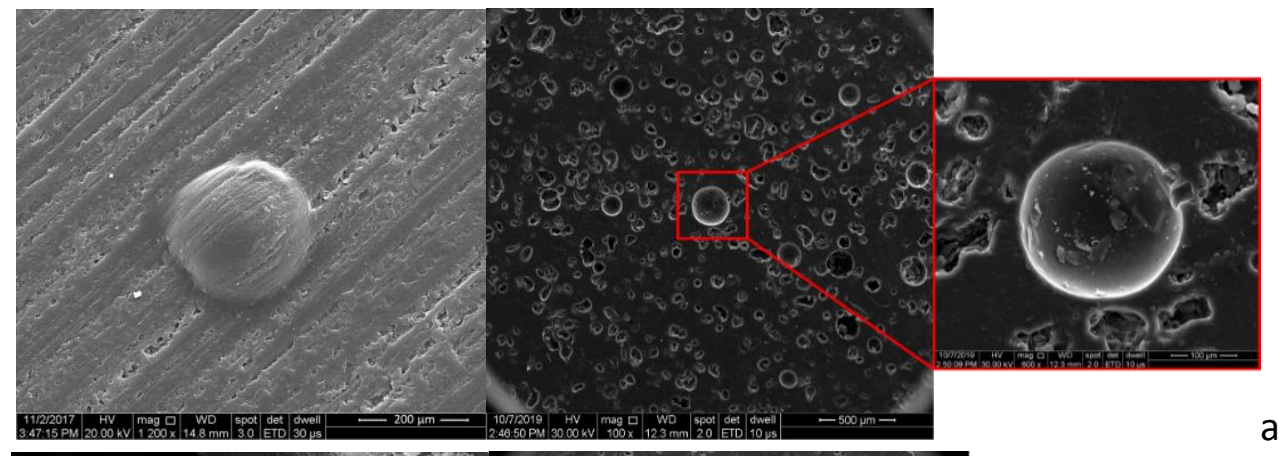

a)

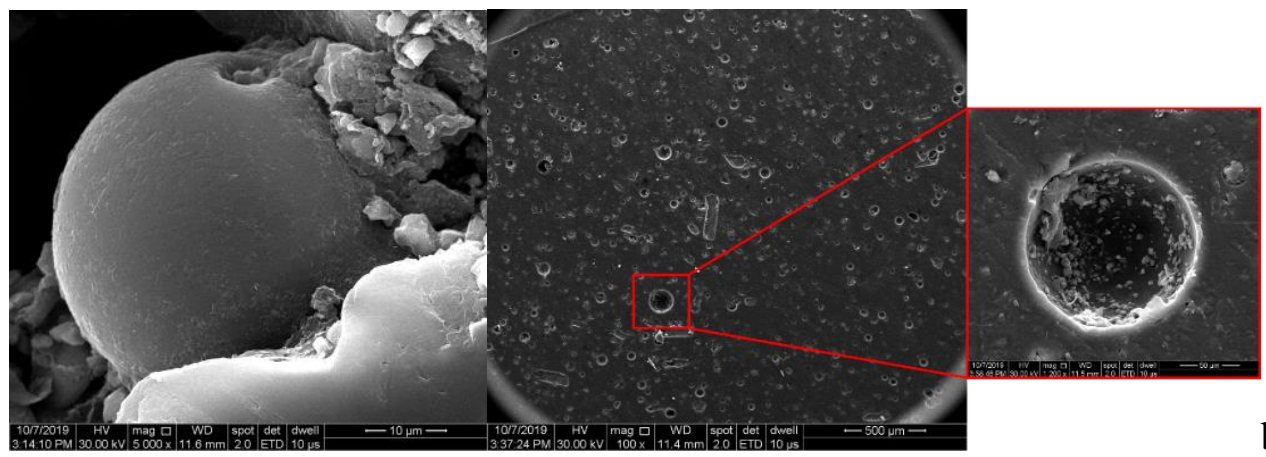

b)

Figure 7. SEM images showing unbroken microcapsules and cavities from sample preparation for a) DCPD system and b) ENB system

\subsection{Three-point bending tests}

Bending tests were performed at a $2 \mathrm{~mm} / \mathrm{min}$ speed rate (Figure 8a) on an Instron 3360 Series. Reference specimens were tested until rupture while specimens containing healing agents were tested until the first crack appears (Figure 8b), more precisely when load is constant, this being the starting point of material degradation. White areas on the specimens after testing represent the crack initiation areas. It was observed that the addition of healing system decreases the mechanical properties of the composite material, healing system acting as an induced defect. This defect decreases the bending strength with an average of $8 \%$ for DCPD healing system and with $10 \%$ for ENB system respectively. Figure 9 presents a comparison between bending strength of tested specimens and figure 10 the loaddisplacement curves for the same specimens.
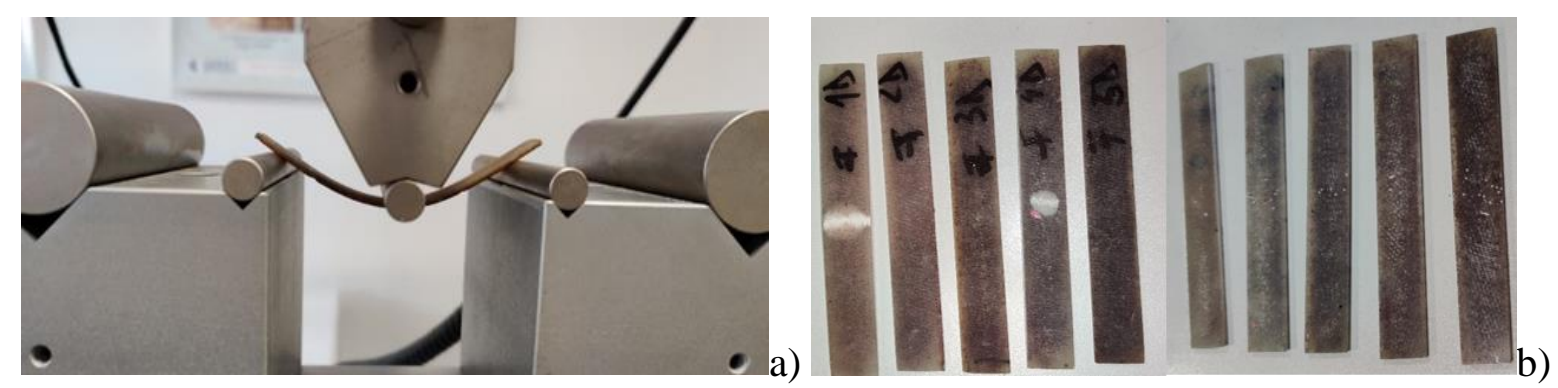

Figure 8. Images a) during the three-point bending test and b) after testing. 


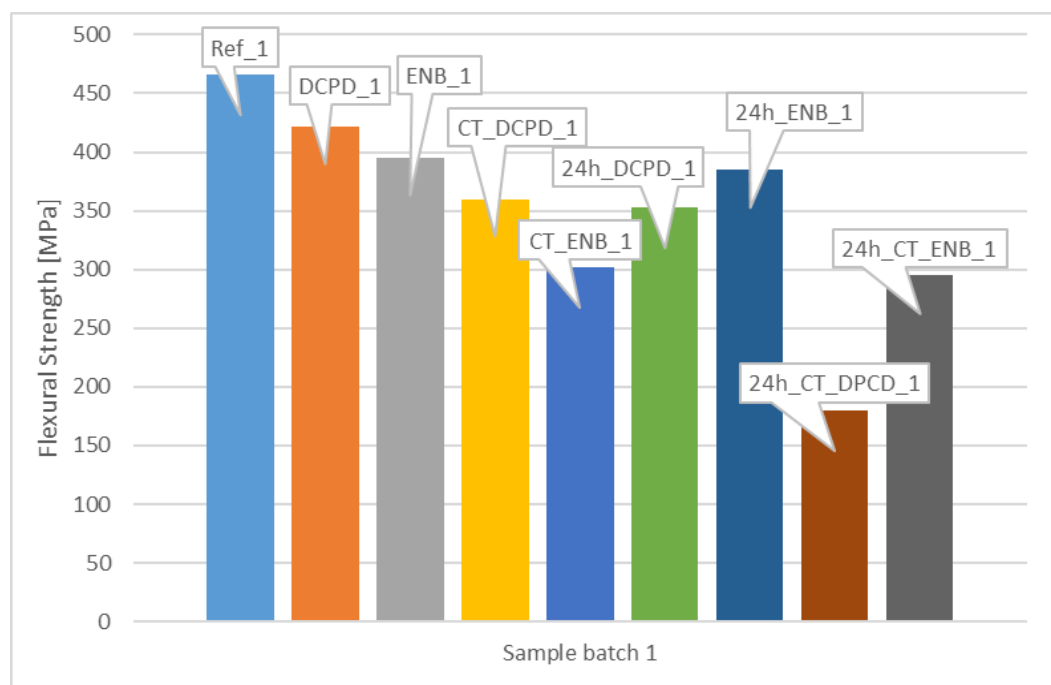

Figure 9. Bending strength of tested samples

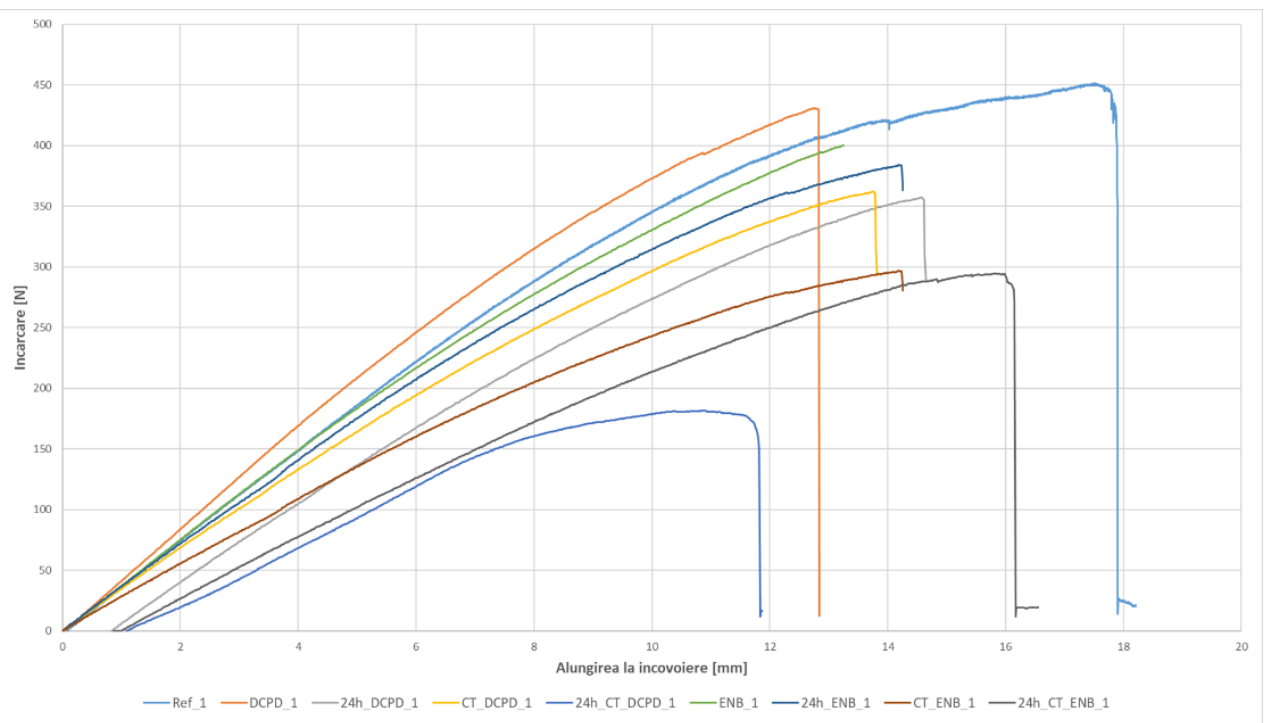

Figure 10. Load-displacement curve of the first set of samples subjected to bending tests

It can be seen from the first set of samples, presented in figure 8 , the bending strength of DCPD system sample has decreased by $8 \%$ and $10 \%$ for ENB system, respectively, compared to the reference sample. After thermal cycling $\left(-20^{\circ} \mathrm{C}\right.$ to $\left.+100{ }^{\circ} \mathrm{C}\right)$, the samples containing DCPD system presented an extensive decrease in bending strength with an average of $22 \%$ and $35 \%$ for ENB system, compared to the reference sample. Tested samples were introduced in an oven at $40{ }^{\circ} \mathrm{C}$ for $24 \mathrm{~h}$ and retested. It is considered that due to this external stimulus, the reaction between the healing agents and the matrix is accelerated. Samples not subjected to thermal cycling and retested after $24 \mathrm{~h}$ showed that in the case of DCPD system, a $24 \%$ drop in bending strength was found compared to the reference sample, and a $16 \%$ drop from the initial DCPD sample. For ENB system, retesting after $24 \mathrm{~h}$ showed a bending strength drop of $17 \%$ compared to the reference sample a $2.5 \%$ drop compared to initial ENB sample. For the samples that were subjected to thermal cycling, retesting after $24 \mathrm{~h}$ showed a $50 \%$ decrease in bending strength for DCPD system compared to first testing and a 57\% decrease compared to the DCPD sample not subjected to thermal cycling. In the case of ENB systems, thermal cycling decreased bending properties by only $3 \%$ compared to first testing and with $22 \%$ compared to ENB sample not subjected to thermal cycling. It can be said that the exposure to thermal cycling is affecting the DCPD system compared to ENB system, mainly because the ENB has a higher negative temperature 
resistance compared to DCPD as well as a higher melting point. The remaining four sets of samples showed an average of approximate bending strength values as the first set.

Figure 11 illustrates the influence of microcapsule volume on the composite bending strength. By increasing the microcapsules volume from $5 \%$ to $15 \%$ it decreases the bending strength of DCPD samples by $12 \%$ and of ENB samples by $16 \%$ compared to the reference samples. As ENB microcapsules have lower density compared to DCPD ones, it requires a higher quantity of microcapsule to be embedded in the composite material. Thus, it is seen that as the microcapsule volume increases it affects the bending strength of the material, mainly by acting first as a defect in the composite and secondly as a healing system.

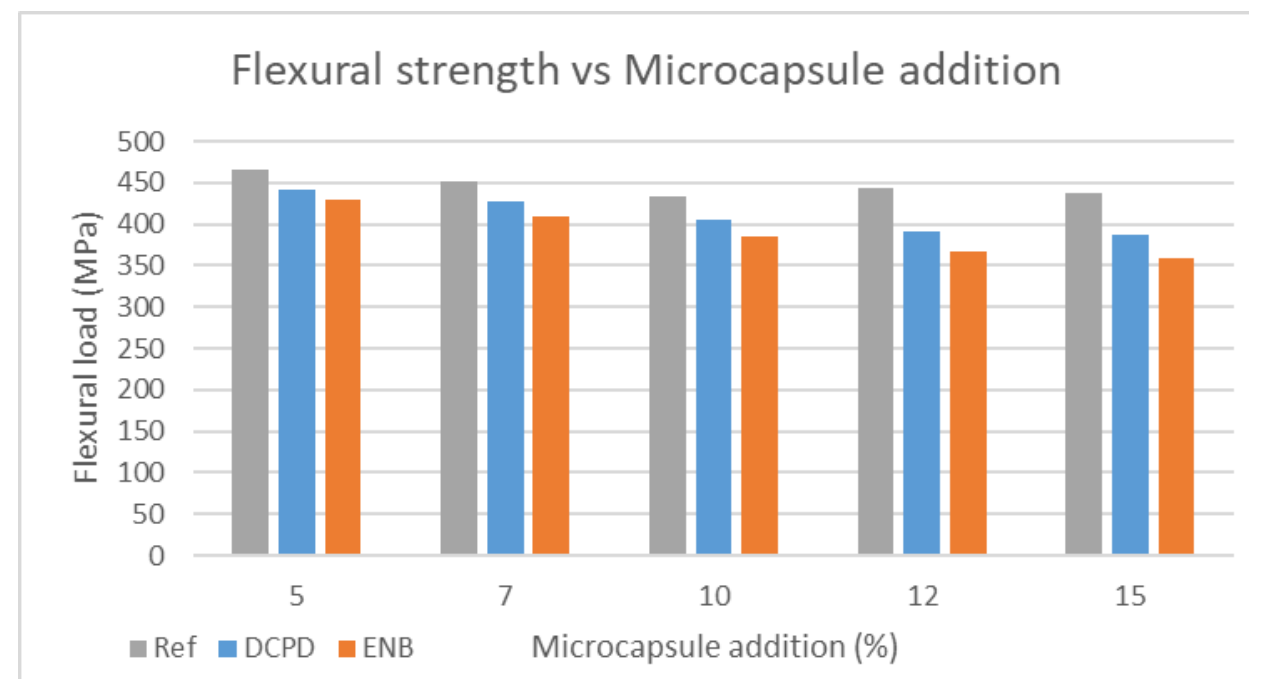

Figure 11. Microcapsule volume influence on bending strength

\section{Conclusions}

As the two healing systems were synthetized by in-situ polymerization, microstructural analysis was conducted to validate microcapsule formation and to observe the dimensions of both healing systems. DCPD microcapsules exhibit diameters ranging between 100 and $250 \mu \mathrm{m}$ while ENB microcapsules show diameters between 30 and $100 \mu \mathrm{m}$. Moreover, FT-IR and DSC analysis have shown the successful fabrication of microcapsules by matching each components wavenumber and glass transition temperature. Three-point tests have shown a decrease in mechanical strength of about $8 \%$ for specimens containing DCPD system and of $10 \%$ for ENB, respectively. After 24 hours, the specimens were re-tested and the healing efficiency was evaluated. For specimens containing DCPD systems, an $83 \%$ healing was observed and $97 \%$ for ENB system. This means that even though the specimens containing ENB healing systems presented a lower bending strength compared to DCPD healing system, after temperature stimulus, the ENB microcapsules were more effective than DCPD ones. Thermal cycling was performed in the range of $-20^{\circ} \mathrm{C}$ to $100^{\circ} \mathrm{C}$ to observe the behaviour of healing systems to constant temperature changes for 12 hours. Exposure to thermal cycling decreases even more the specimens with DCPD healing system compared to ENB system, basically due to the temperature resistance of microcapsule constituents. Retesting after 24 hours presented an even more drastic decrease of bending strength for DCPD specimens compared to ENB one. Therefore, it can be concluded that ENB healing system was more effective compared to DCPD system, as the ENB microcapsule constituents are more temperature resistant and more chemically compatible with the composite material matrix.

Acknowledgements.This fabrication process of healing agents and composite samples as well as microstructural analysis was carried out within "NUCLEU" Program TURBO 2020+, Grant no. 2N/2019, supported by the Romanian Minister of Education and Research. 
This work is supported by the project ANTREPRENORDOC, in the framework of Human Resources Development Operational Programme 2014-2020, financed from the European Social Fund under the contract number 36355/23.05.2019 HRD OP /380/6/13 - SMIS Code: 123847." The authors are grateful for all members from the INOVABIOMED project, ID: P_36_611:145/26.10.2016, http:// www.inovabiomed.upb.ro/ and the University POLITEHNICA of Bucharest for technical support. Also, the authors would like to thank the editors and anonymous reviewers.

\section{References}

1. P.K. MALLICK, Fiber-Reinforced Composites: Materials, Manufacturing and Design; CRC Press: Boca Raton, FL, USA, 2007

2. M.Q. ZHANG, M.Z. RONG, Basics of self-healing: State of the art. In Self-Healing Polymers and Polymer Composites; John Wiley \& Sons: Hoboken, NJ, USA, 2011; pp. 1-81

3. K. MPHAHLELE, S. S. RAY, A. KOLESNIKOV, Self-Healing Polymeric Composite Material Design, Failure Analysis and Future Outlook: A Review, Polymers 2017, 9, 535; doi:10.3390/polym9100535

4.A.M. PETERSON, H, KOTTHAPALli, M.A.M. RAHMATHULlAH, G.R. PALMESE, Investigation of interpenetrating polymer networks for self-healing applications. Compos. Sci. Technol. 2012, 72, 330-336

5. WHITE, S., SOTTOS, N., GEUBELLE, P. et al. Autonomic healing of polymer composites. Nature 409, 794-797 (2001). https://doi.org/10.1038/35057232

6. V. GIURGIUTIU, A. CUC, Embedded Non-destructive Evaluation for Structural Health Monitoring, Damage Detection, and Failure Prevention, The Shock and Vibration Digest, Vol. 37, No. 2, March 2005 83-105, DOI: 10.1177/0583102405052561

7. D.J. TITMAN, Applications of thermography in non-destructive testing of structures, NDT \& E International Volume 34, Issue 2, March 2001, Pages 149-154, https://doi.org/10.1016/S09638695(00)00039-6

8. K. JUD, H. H. KAUSCH, AND J. G. WILLIAMS, Fracture mechanics studies of crack healing and welding of polymers, Journal of Materials Science, vol. 16, no. 1, pp. 204-210, 1981

9. C. DRY, Procedures developed for self-repair of polymer matrix composite materials, Composite Structures, Volume 35, Issue 3, July 1996, Pages 263-269

10. B.J. BLAISZIK, S.L.B. KRAMER, S.C. OLUGEBEFOLA, J.S. MOORE, N.R. SOTTOS, S.R.WHITE, Self-Healing Polymers and Composites, Annu. Rev. Mater. Res. 2010. 40:179-211, doi:10.1146/annurev-matsci-070909-104532

11. B. AISSA, D. THERRIAULT, E. HADDAD, W. JAMROz, Self-Healing Materials Systems: Overview of Major Approaches and Recent Developed Technologies, Advances in Materials Science and Engineering, Volume 2012, Article ID 854203, doi:10.1155/2012/854203

12. R.S. TRASK, H.R. WILLIAMS, I.P. Bond, Self-healing polymer composites: mimicking nature to enhance performance, Bioinspiration\&Biomimetics, 04/2007; 2(1):P1-9, DOI:10.1088/17483182/2/1/P01

13. R. KUMAR, N. R. J. HYNES, R. MANJU, P. Senthamaraikannan, S.S. Saravanakumar, A. Khan, S.R.S. Bharathi, A. M. Asiri, I. Khan, M. M. Ali Khan, F. Verpoort, Self-healing fiber-reinforced epoxy composites, Self-Healing Composite Materials. DOI: https://doi.org/10.1016/B978-0-12817354-1.00020-X

14. R.S. TRASK, C.J. NORRIS, I.P. BOND, Stimuli-triggered self-healing functionality in advanced fibre-reinforced composites. J Intell Mater Syst Struct 2014; 25:87-97, https://doi.org/10.1177/ 1045389X13505006

15. M.R. KESSLER, S.R. White. Self-activated healing of delamination damage in woven composites. Composites Part A: Appl Sci Manuf 2001; 32:683-99.

16. B.J. BLAISZIK, M.M CARUSO, D.A. MCILROY, J.S. MOORE, S.R. WHITE, N.R. SOTTOS. Microcapsules filled with reactive solutions for self-healing materials. Polymer 2009; 50:990-7. 
17. R. WANG, S. ZHENG, Y.G. ZHENG. Polymer matrix composites and technology, Woodhead Publishing Series in Composites Science and Engineering; 2011. p. 1-568.

18. P. SHABANI, M.M. SHOKRIEH, A. SAEEDI, A novel model to simulate the formation and healing of cracks in self-healing cross-ply composites under bending loading, Composite Structures 235 (2020) 111750

19. C. WANG, H. WANG, L. SHEN, J. HOU, Q. XU, J. WANG, X. CHEN, Numerical simulation and experimental study on crack self-healing in BK7 glass, Ceramics International 44 (2018) 18501858, http://dx.doi.org/10.1016/j.ceramint.2017.10.121

20. T. D. P. THAO, Quasi-Brittle Self-Healing Materials: Numerical Modelling and Applications in Civil Engineering, Ph.D. thesis, Department of Civil and Environmental Engineering National University of Singapore, 2011

21. XANDER K.D. HILLEWAERE, FILIP E. DU PREZ, Fifteen chemistries for autonomous external self-healing polymers and composites, Progress in Polymer Science 49-50 (2015) 121-153

22. D.G. BEKAS, K. TSIRKA, D. BALTZIS, A.S. Paipetis, Self-healing materials: A review of advances in materials, evaluation, characterization and monitoring techniques, Composites Part B 87 (2016) 92-119

Manuscript received: 28.02 .2020 